\title{
Cartas y viajes de ida y vuelta: diálogos bifronterizos en las novelas epistolares de Ana Castillo y Rosina Conde*
}

\author{
Edith Mora Ordóñez**
}

\section{Resumen}

El presente estudio propone la comparación biborderlands o bifronteriza de dos novelas epistolares escritas desde ambos lados de la frontera México-Estados Unidos: Las cartas de Mixquiahuala (1986), de la chicana Ana Castillo, y La Genara (1998), de la mexicana Rosina Conde. El diálogo a través de las cartas en dichas obras constituye un encuentro especular que permite a las mujeres desdoblarse y mirarse a sí mismas. Desde las dos fronteras comparten experiencias de ruptura de las estructuras dominantes familiares, masculinas y patriarcales. La conversación epistolar incide en un proceso autoreflexivo, de reconocimiento y conformación de nuevas identidades y subjetividades femeninas.

Palabras clave: bifronterizo, sujeto femenino, escritura epistolar, especularidad, subjetividad.

\section{Travels and Back and Forth Letters: Biborderlands Dialogues in Epistolary Novels of Ana Castillo and Rosina Conde}

\begin{abstract}
This study proposes comparing biborderlands or bi-frontier review of two epistolary novels written from both sides of the border Mexico-United States: Mixquiahuala letters (Las cartas de Mixquiahuala, 1986), of Chicana Ana Castillo, and La Genara (1998) of the Mexican Rosina Conde. The dialogue through the letters in these works is a speculate encounter that allows women to unfold and look at themselves. From the two borders they share breakdown experiences of family, male and patriarchal dominant structures. The epistolary conversation have an impact on a self-reflective process, recognition and configuration of new identities and female subjectivities.
\end{abstract}

Keywords: Biborderlands, Epistolary Writer, Female Subject, Subjectivity, Specularity.

Este artículo se inscribe en la investigación Fondecyt de Postdoctorado No. 3150075 titulada "El sujeto femenino en las literaturas de la frontera México-Estados Unidos: una perspectiva bifronteriza" (2015-2016), con patrocinio de la Pontificia Universidad Católica de Chile.

** Mexicana. Doctora en Literatura y Comunicación. Programa Interdisciplinar en Estudios Culturales por la Universidad de Sevilla, España. emoraordonez@gmail.com 


\section{Introducción}

Los numerosos planteamientos teóricos acerca de la frontera mexicana-estadounidense proponen la idea de una franja porosa, dinámica y compleja, debido a las tensiones generadas por la imposición de barreras políticas y culturales, así como la conformación de estructuras simbólicas que desestabilizan las nociones de límite. El enfoque literario sobre las fronteras simbólicas requiere avanzar en la inclusión de los imaginarios de ambos lados, es decir, el norte de México y el sur de Estados Unidos, tener en cuenta que las identidades se diversifican de acuerdo con las prácticas de los sujetos en los bordes de cada país. Este estudio propone la interpretación de dos novelas epistolares escritas por autoras desde el sur de Estados Unidos y el norte de México: Las cartas de Mixquiahuala (1986), de la escritora chicana Ana Castillo, y La Genara (1998), de la escritora mexicana Rosina Conde, las cuales ponen en diálogo y tensión problemáticas de las mujeres vinculadas con su situación y experiencia fronteriza.

El propósito es identificar claves de sentido representadas en los textos de dichas autoras para determinar aspectos del viaje o desplazamiento y, en particular, del intercambio de mensajes a través de la escritura epistolar entre mujeres, que constituyen diálogos o procesos transdiscursivos con efectos especulares. Específicamente, establecer, a partir de un ejercicio comparativo, relaciones entre las obras, enfocadas en la trasgresión de los personajes y la conformación de nuevas identidades femeninas, al margen de las normas del sistema patriarcal en este contexto.

Se busca, por un lado, recuperar nociones teóricas en relación a la escritura epistolar, con el objetivo de comprender su función dentro de las prácticas de reflexión, transgresión y empoderamiento de los sujetos femeninos. En cuanto al abordaje metodológico se realiza un estudio comparativo desde una perspectiva de análisis "bifronteriza", dado que pretende responder a los planteamientos que advierten la tendencia de los críticos mexicanos y chicanos a realizar estudios unilaterales acerca de las literaturas de ambas franjas de la frontera mexicana-estadounidense (Hernández 32). Se propone, entonces, pasar "de la crítica borderlands a la crítica biborderlands", en palabras de Antonio Cárdenas (56), puesto que son muy escasos los trabajos que relacionan las dos producciones fronterizas (Hernández 55) ${ }^{1}$.

La bibliografía de textos críticos de la literatura chicana supera a la que presenta la literatura de la frontera en el norte de México. La académica María Socorro Tabuenca (2013) habla de un "colonialis- 
Se advierte, tanto en La Genara como en Las cartas de Mixquiahuala, que lo fronterizo representa un espacio geográfico y refiere, en ese sentido, desplazamientos y cruces territoriales; pero, sobre todo, se manifiesta en la presencia de límites sociales, culturales, de género, étnicos y generacionales de los personajes. La frontera irrumpe como experiencia cotidiana para los sujetos situados en los márgenes, en su posición frente a otros espacios y otros sujetos, caracterizados, en este caso, por códigos arraigados al sistema patriarcal. El intercambio de cartas constituye para las mujeres un encuentro especular que les permite pensarse y mirarse en doble perspectiva, es decir, reconocerse a sí mismas a partir de la escritura-lectura propia y a través de la escritura-lectura de la otra con la que establece la correspondencia. En los relatos de Conde y Castillo hay una reconstrucción de experiencias liberadoras a partir del viaje, las cuales contrastan con escenarios de opresión de la vida cotidiana. La escritura epistolar de los personajes femeninos ahonda en la autoreflexión y el reconocimiento de sus subjetividades.

Se observan, anticipadamente, diversos efectos especulares, es decir, coincidencias. Primero en una instancia individual, cuando el sujeto femenino reflexiona acerca de sí mismo, se mira en el espejo desde que emprende el ejercicio de la escritura; segundo, de una interlocutora a otra, al compartir, identificarse o diferenciarse durante el intercambio de experiencias y, por último, un reflejo discursivo de una novela a otra, de frontera a frontera, o de la escritura mexicana a la escritura chicana $-\mathrm{y}$ viceversa-. En este último cruce de sentidos se presentan diferencias de imaginarios y discursos, pues aun cuando los personajes confluyen en la búsqueda y el viaje de carácter iniciático, motivado por la necesidad de transgredir las normas patriarcales, no comparten las mismas situaciones respecto a su lugar de partida, así como las formas de entender y definir sus identidades.

mo o hegemonía intelectual" ejercida por los estudios posdeconstructivistas fronterizos desde Estados Unidos, los cuales restringen la problemática a su contexto y excluyen a sus referentes primarios en el lado mexicano ("Las literaturas" 395). Según esta afirmación, se propicia una literatura dominadora (la chicana) y una dominada (la de la frontera) (394). Específicamente, Graciela Silva Rodríguez (2010), académica mexicana radicada en Estados Unidos, desarrolla un primer "modelo feminista biborderlands", aplicado a la literatura escrita por mujeres pues, señala que "se considera a la reflexión teórica feminista multinivelada como la más importante aportación para una nueva comprensión bilateral de la historia, la cultura y la sociedad fronteriza en ambos lados de la línea" (57). 


\section{Las novelas epistolares de Rosina Conde y Ana Castillo}

Las escritoras chicanas y mexicanas de la frontera norte dialogan mediante los "discursos feministas contrahegemónicos que entienden identidades y culturas como transformativas, en constante re(definición) y (re)contextualización" (Klahn 126). Sus textos coinciden al "compartir y problematizar conceptos de nación y feminismo" (112). Borderlands/La frontera: The New Mestiza (1987), el conocido ensayo de Gloria Anzaldúa, constituye un primer texto reinvindicativo, fundamental para la interpretación de las fronteras simbólicas y de sus cruces desde el punto de vista chicano. Su propuesta acerca de la configuración de la "New Mestiza" establece una pugna por la legitimación de las identidades subjetivas.

Rosina Conde, originaria de Baja California, es una de las escritoras más reconocidas dentro de la literatura del norte de México. Su libro, La Genara, incluye un conjunto de cartas que fueron inicialmente publicadas como entregas en el suplemento cultural de un diario de la ciudad de Tijuana y posteriormente reunidas en una novela epistolar. La protagonista, Genara, es una mujer joven que vive en la fronteriza Tijuana, quien se encuentra en medio de un proceso de divorcio y mantiene correspondencia por correo electrónico con su hermana Luisa, la cual, después de divorciarse, realiza estudios de posgrado en la Ciudad de México. Las cartas de Genara y Luisa, junto con algunos mensajes intercambiados vía fax con sus padres, refieren los conflictos enfrentados por las mujeres al pretender romper con el orden social y cultural en las ciudades provincianas de dicho país, caracterizadas en la novela como espacios de control patriarcal, de apego a la tradición y a las normas religiosas, en contraste con la dinámica de vida cosmopolita de la capital mexicana. La académica Graciela Silva Rodríguez (2010) destaca, en su lectura de La Genara, "la articulación de la novela a partir del género epistolar, lo que posibilita una severa especie de denuncia novelada de los distintos capítulos de la estructura patriarcal" (168).

Ana Castillo es una autora representativa de la literatura de mujeres chicanas iniciada por Gloria Anzaldúa. Sus obras han sido escritas originalmente en inglés y traducidas al español. The Mixquiahuala Letters o Las cartas de Mixquiahuala reúne treinta y ocho cartas que Teresa, una mujer chicana, dirige desde Los Ángeles y Chicago a su amiga Alicia, también de descendencia hispánica, radicada en Nueva York. Las cartas de Teresa -pues las respuestas de Alicia no se incluyen 
en el libro- reconstruyen los trayectos y vivencias fronterizas de las dos amigas durante un viaje realizado a México con el objetivo de reencontrar sus raíces e identidades mexicanas. En ellas se exponen los conflictos culturales que enfrentan al comportarse como mujeres estadounidenses, dentro de un entorno dominado, según el relato, por el sistema patriarcal, y donde son reconocidas o tratadas, a pesar de su origen latino, como extranjeras. Desde la crítica chicana, Alvina Quintana (1994) considera que esta novela puede ser vista como una parodia etnográfica moderna, donde la forma epistolar funciona:

as a vehicle, enabling her to move freely from one issue to another, from one country to another as she describes the relationship between the sexes. But more importantly, it is the epistolary from which gives her the flexibility to describe the differences between the way women are viewed in the United States and Mexico. (81)

\section{La carta: espacio de cruce y reconstrucción de las identidades}

La carta, escritura mediante la cual las mujeres consiguieron trascender del espacio privado al espacio público y expresarse libremente desde la intimidad, permitió su introducción en el ámbito literario del cual habían sido excluidas. Este proceso ha supuesto, igualmente, un desafío al control de los espacios masculinos y patriarcales, como señala Meri Torras Francés (2001):

Históricamente, en su paulatino acceso a la escritura pública, las mujeres han debido situarse en una paradoja situacional, fruto del hecho de tener que escribir dentro de una corriente hegemónica -que no había sido trazada por ni para las mujeres-, y, a la vez, desde el ejercicio tolerado de la escritura, encontrar las estrategias para modificarla, transgredirla, subvertirla. (76)

La aprobación de la escritura epistolar de las mujeres, agrega Torras Francés, en el siglo XVII, momento en que se hace pública, exigía la transición de la naturalidad del lenguaje femenino hacia los recursos y artificios literarios que caracterizaban a la escritura masculina. Debían, por lo tanto, apegarse a la virtud y a la moral de la época. Más adelante, 
el "estilo femenino" de la carta privada, caracterizada por una "escritura más espontánea, menos estructurada, más emocional”, se convertiría, inicialmente, en un modelo para la construcción de la novela epistolar (Ciplijauskauté 63). Como una ventana, la escritura de la carta abre el acceso al universo interior femenino y hace efectiva la afirmación de su subjetividad. Además, por la amplitud y diversidad de asuntos abordados, así como de tonalidades de escritura, representa una instancia caleidoscópica, funciona como membrana de traducción de múltiples mensajes o códigos. Es vehículo o trayecto mismo de significaciones, de manera que entraña un discurso semiotizado, pues en ésta "la inscripción textual de la situación de la enunciación [...] da lugar a determinados efectos de sentido" (Doll, "La carta privada" párr. 32). Por su función comunicativa, por las implicaciones que tiene en el remitente y en el destinatario, y debido a que su interpretación inserta los contextos de escritura y de lectura, constituye un discurso pragmático. De hecho, según Darcie Doll, la novela epistolar puede leerse como una "práctica cultural" (párr. 4).

El intercambio de mensajes anula simbólicamente el espacio de separación de los agentes que participan en este "diálogo diferido" (Violi, "La intimidad de la ausencia" 89), instala un puente de cruce hacia otro lado y hace posible la presencia - "ausente", diría Patrizia Violi (89)- de la otra a la cual se dirige. En dicho ejercicio tiene lugar un doble proceso de escritura y de lectura que comprende, primero, la decodificación de las propias ideas mediante el acto de escribir y se completa con la traducción de los mensajes leídos en la respuesta recibida. Posteriormente, estas interpretaciones generan nuevos mensajes que vuelven a ponerse en tránsito, nuevas esperas con dudas suspendidas, entre las cuales se forman expectativas. Se generan, entonces, otras lecturas y traducciones, enseguida intervenidas desde la reflexión para incluirse y debatirse en este campo dinámico de correspondencia.

Tanto la escritura como la lectura constituyen actos individuales, por lo cual se considera que el primer diálogo instaurado en el intercambio de cartas es un un ejercicio discursivo autorreferencial, de la interlocutora que escribe a otra y "se escribe", o bien, que lee a otra mientras "se lee". Los planteamientos de Bajtin (1999), Foucault (2012) y Butler (2007), en relación con la carta, son útiles para observar la función de ésta en la que, partiendo de una escritura del sujeto mismo, incide en el proceso de construcción identitaria (Fernández Cordero 24-25). En la comunicación discursiva, especialmente en el diálogo de la correspondencia, Bajtin 
señala que los mensajes enunciados, estructurados para el otro, se anticipan a la respuesta. Se genera una actitud previa hacia el discurso del otro, el cual determina y regula lo enunciado. ${ }^{2}$

De acuerdo con esta idea, Pedro Salinas menciona que quien escribe la carta se convierte en el primer remitente, por esa razón, anota: "escribir es cobrar conciencia de nosotros” (ctd. por Guillén 185). Mientras tanto, la figura del otro, de la otra, a quien se dirige la carta, actúa como referente o "colaborador silente" (Martin 33); se considera, para el remitente, una figura de lector modelo o lector ideal, el cual, en su complicidad, posee la información necesaria para decodificar el mensaje y responder acertadamente. En Las cartas de Mixquiahuala se incluyen únicamente las cartas de ida escritas por Teresa. Las cartas de vuelta, que corresponden a Alicia, no aparecen. Esta ausencia de respuesta deja entredicha la función de la carta como un proceso autoreflexivo. La suposición de Alicia en un lugar distante, la amistad como un encuentro especular que permite la posibilidad de desdoblarse y mirarse en perspectiva, facilita la autodefinición del personaje femenino en su búsqueda de identidad.

El ejercicio de escritura de las cartas, señalaba Foucault, es una práctica de "uso para sí" (343). En el intercambio de correspondencia, el sujeto "practica una gimnasia que se dirige al otro pero también a él mismo y le permite [...] mantenerse constantemente en estado de autodirección" (344). Finalmente, en medio de esta interpretación de múltiples discursos mediados por diversos contextos históricos, sociales y culturales, surge la propuesta de Butler desde los planteamientos feministas que incorporan las nociones de subjetividad y performatividad: el sujeto, en sus múltiples deplazamientos, se conforma en identidades flexibles, no fijas; efectúa, a través del discurso y en un espacio de acción que desestabiliza las normas, un proceso performativo, mediante el cual se representa, reconstruye y resignifica.

Dichas pautas se retoman aquí para hablar de efectos de especularidad en un espacio fronterizo, donde la carta constituye,

En palabras de Bajtin (1999), "un solo individuo cumple con dos papeles y lo que importa es, precisamente, esta diferenciación de roles. El enunciado de aquel a quien contesto (y con quien estoy de acuerdo, o estoy refutando, o cumplo su orden o tomo nota, etc.) ya existe, pero su contestación (o su compresión activa) aún no aparece. Al construir mi enunciado, yo trato de determinarla de una manera activa; por otro lado, intento adivinar esta contestación, y la respuesta anticipada a su vez influye activamente sobre mi enunciado" (286). 
como se dijo, un proceso de cruce y traducción de códigos culturales. $\mathrm{Al}$ implicar a sujetos femeninos, las cartas funcionan como instrumento de contacto y expresión, instrumentos de diálogo que permiten la transición o desplazamiento simbólico de un lugar y de una condición a otra. La carta, argumenta Darcie Doll (2004), "constituye un territorio excepcionalmente favorable de ser apropiado desde la marginalidad de las mujeres ante los discursos hegemónicos" (154). Se entiende que el espacio de intercambio epistolar, en su carácter fronterizo, es también heterogéneo y productivo.

\section{El viaje y la búsqueda del lugar de afirmación}

Las situaciones de enunciación o contextos desde los cuales escriben los personajes difieren en las obras analizadas. En la novela de Ana Castillo, Teresa y Alicia realizan un viaje a México; la primera de ellas tiene el propósito de reconstruir su identidad ligada al imaginario del pasado mexicano precolombino. Vive en un lugar de Estados Unidos que nunca describe y le es aparentemente indiferente, pues, señala en una carta, siente que no pertenece a él; escribe que "había un llamado definitivo para encontrar un lugar que satisfaciera mi espíritu anhelante, la india que en mí había comenzado a curar las aflicciones [...] razones para buscar el pasado en visitas a la riqueza de ruinas antiguas" (69). En Mixquiahuala, un pueblo mexicano localizado en el centro de México, observa a la gente y comprende el origen del "exótico matiz amarillo y rojo de [su] piel, la insinuación de acento en [su] discurso barroco y el origen indescifrable de [su] ser" (31). Por otra parte, Genara, en la novela de Rosina Conde, recrea un escenario de Tijuana mediante la descripción de sus experiencias cotidianas, haciéndola ver como un lugar periférico, pues aun cuando es una ciudad grande, conserva un ambiente tradicional o conservador, del cual sus habitantes escapan con frecuencia, cruzando la frontera hacia San Diego, la colindante ciudad estadounidense. Genara intenta sostener un modo de vida apegado a las normas, influido por los prejuicios morales de la gente, en contraste con la dinámica social de la Ciudad de México, donde vive su hermana Luisa. Allí, descubren prácticas y reglas de comportamiento distintas, menos restringidas y más liberales para las mujeres.

En ambos relatos, el lugar de destino es el centro de México, pero en el de Castillo el trayecto de viaje está dirigido a los espacios naturales e 
históricos -idealizados por el imaginario exótico asociado a las ruinas precolombinas-, mientras que, en el de Conde, se enfoca en el escenario urbano, modernizado y cosmopolita. Los desplazamientos de Genara y de Luisa obedecen a la insatisfacción con un entorno de opresión, frente a la familia regida por el orden patriarcal y las escasas oportunidades que tienen para realizar un proyecto profesional e independizarse. Luisa, quien contrarió las reglas a partir del divorcio, fue la primera en escapar: “[...]no se me ocurrió otra cosa que venirme huyendo de Tijuana. Los cursos en la universidad van bien. Es mucho el trabajo, pero me sirve [...]: Creo que tú deberías hacer lo mismo y salir de allí” (Conde 27).

Después de concluir los viajes, cobra fuerza la necesidad de alejarse de la casa familiar, alimentada por la curiosidad y la ensoñación acerca de nuevas oportunidades de vida. Luisa viaja a Tijuana con desánimo para visitar a sus padres y, cuando en la Ciudad de México experimenta sensaciones de aprisionamiento por el trabajo y el ritmo de vida sofocante, encuentra un paraíso en la casa de su amiga, en Cuernavaca. Genara visita los mismos lugares que su hermana y, además, va ocasionalmente a San Diego. Por otro lado, Teresa y Alicia realizan un recorrido turístico por varias ciudades del centro y el sur de México y, luego, cuando vuelven a Estados Unidos, se desplazan entre Chicago, Nueva York y Los Ángeles, por motivos de trabajo o descanso y, desde allí, se envían cartas.

En ambas novelas, el lugar de partida u origen representa un espacioborde de incertidumbre, un umbral en el que se tensan las convicciones sobre la identidad y las prácticas de vida. Por esta razón, Teresa decide "iniciar un proceso metódico de reconstruir los pedazos" (Castillo 163) que conforman esa figura femenina fragmentada, en ese sentido fronteriza. El viaje de huida tiene como propósito, según señala Teresa en una de sus cartas a Alicia, "el sugimiento de la mujer nueva" (45), a partir del ejercicio de su libertad. En su visita a Mixquiahuala:

quería volar en busca de arcoiris míticos [...] sin honrar las tradiciones patriacales y quería liberarme de la mano protectora de mi marido, de vacaciones con la familia y la familia política guiada por un Dios contradictorio, la sociedad, las señales de tránsito y, sobre todo, mi pobreza, su monotonía. (34)

En la novela de Conde, Genara se enfrenta a la misma situación de encierro y represión, por ello decide, según sus palabras, "no pensar igual", divorciarse y enfrentarse al desacuerdo de sus padres y a las recriminaciones de la sociedad. Fantasea con marcharse, como hizo 
la mujer de su primo, quien "se fue nomás así porque sí: que dizque quería cambiar de vida" (Conde 14). Luisa, mientras tanto, ya ha dejado la ciudad fronteriza, según apunta en una carta: "huyendo de la familia y de los chismes del trabajo. [...] No sabía quién era ahora que estaba sola, [...] me di cuenta de que ni siquiera tenía una percepción adecuada de mí misma" (Conde 201). Si bien los personajes desafían principalmente la tiranía patriarcal, también evaden el castigo de las madres que inculcan la dependencia hacia el hombre como deber y único medio de subsistencia. Fuera de la casa familiar se enfrentan a la crítica social, tanto de hombres como de mujeres y, enseguida, se encuentran en un espacio de indefinición, en el cual se inicia su reconfiguración identitaria.

Dicho esto, el sentido reivindicador de la libertad de las mujeres, a partir de los viajes relatados en las cartas, radica en la reconstrucción de los recorridos. Se trata de viajes vinculados a la memoria y a la imaginación, puesto que los personajes proyectan posibles panoramas para el futuro a partir de sus recuerdos. El artificio de la escritura desde diversos puntos de localización y diversas situaciones, que son supuestas porque no constan ni a una ni a otra en la distancia, pone a los personajes sobre una tela fronteriza de realidades y ficciones. Mientras que la carta suele llevar en sí un acto de confesión, en el caso de la escritura epistolar se presenta la posibilidad de introducir elementos imaginados. Claudio Guillén (2007) habla de una "tendencia ficticio-ficcional" (183) en la construcción de los mensajes epistolares. La ficcionalidad establece un puente entre el lenguaje epistolar y el discurso literario, según el mismo autor, pues en la carta hay “invención” y "niveles de liberación”, en la medida en que el escritor de ésta elabora imágenes permeadas por preferencias, deseos e imaginaciones propias (185).

El viaje a Mixquiahuala le permite a Teresa reencontrar rasgos de su identidad mexicana y confirmar que se compone de una mixtura de elementos: precolombinos, mexicanos, estadounidenses, chicanos, fronterizos; rasgos no definitivos, sino constantemente cambiantes. Sin embargo, no consigue adaptarse en México, pues no es aceptada completamente por la gente que ve en ella a la "gringa" $y$, finalmente, confirma Debra Castillo (1994) en su análisis de la novela, "ninguna de las dos culturas satisface su espíritu" (mi trad.; 102). En las líneas escritas a Alicia intenta materializar el sueño de la mujer libre sobre el lugar mítico de Aztlán, situado en la frontera sur de Estados Unidos, el territorio mexicano donde se revive el primer signo de pérdida y la 
primera fractura identitaria de los mexicanos despojados de su lugar de origen. El personaje contempla y describe su "corazón rodeado de serpientes" (59), afirmando su ascendencia indígena precolombina. Es a través de las cartas como consigue trascender simbólicamente la frontera de su raza y de su cultura chicana, subalterna, todavía impenetrable, para reivindicar su origen mexicano. Teresa recuerda y narra una manifestación de mujeres chicanas, mexicanos y negros, realizada en 1976: "Los días son eternos, secos, calientes; comenzó una sequía agua medida petróleo precioso. Lo llamábamos enero, junio, hojas de otoño verde constante. El País de las Maravillas, recuéstate, viaja en la calle, mimos, payasos, malabaristas, mercachifles de polvo mágico invisible" (57). En estas escenas de la memoria, con tintes de imaginación, Teresa recrea idealmente el episodio de una protesta colectiva con imágenes de la libertad que anhela.

Luisa, en un contexto distinto, describe el relato amoroso de una historia que no existe y termina desmintiéndolo en una de las últimas cartas a Genara:

Mis historias sobre Francisco y Jorge no fueron nada más que un alucine para demostrarte que no estaba blindada emocionalmente. Yo quería demostrarte, de alguna manera, que yo también era capaz de tener relaciones [...] Sin embargo, como me daba cuenta de que no podía tenerlas, tuve que inventármelas...(Conde 202-203)

De esta manera, la carta ofrece a los personajes la oportunidad de dar un giro a la imposibilidad mediante la creación de espacios deseados que adquieren carácter de real al obtener la "colaboración" y la "complicidad" del destinatario (Guillén 187). Se logra en los casos citados cuando la lectora lo acepta en su lectura y lo confirma como cierto entre los comentarios expuestos en su respuesta.

La mayoría de las cartas de Teresa describen recuerdos y evocan lugares que parecen haberse borrado; la idea de distancia física es más nítida y la destinataria se percibe más lejana. El discurso nostálgico, que constantemente remite al pasado, hace de la epístola un medio que acerca y separa a la vez a los personajes, como señala Patrizia Violi (1987): "evoca la presencia del otro y al mismo tiempo lo coloca en un lugar [...] inalcanzable: si escribo es porque el otro no está aquí, si lo está, es precisamente para alejarlo" (96). Esta condición o "dialéctica de 
proximidad y distancia" (96) es más notoria en los mensajes de Teresa, puesto que no solo recrea las vivencias propias, sino que reconstruye también las de su amiga, volviendo más difusa la presencia de ésta en el relato. El personaje recurre a los momentos que compartieron juntas durante el viaje con el propósito de organizar y satisfacer, a través de dicha "escritura liberadora", esa inquietud personal que motiva la huida y la búsqueda.

Si bien se desconocen las cartas de Alicia, Teresa da señas de sus rasgos mediante el uso de vocativos e interpelaciones como "Alicia, ¿recuerdas?" (56), las cuales son una solicitud de contestación. Así, la figura de Alicia representa lo que según Guillén sería "casi un pretexto”, cuando en la carta no hay "interpelación del todo, sino también expresión solitaria y casi monólogo, privado como tal, pura escritura liberadora" (190).

Antes de que las imágenes sobre el trayecto a México terminen diluyéndose, Teresa revisita aquel espacio vivido y lo describe. El viaje marca un antes y un después en su proceso de transgresión. Mientras piensa las cartas, evalúa cambios, evoluciones, estancamientos o retrocesos. Revisa la utilidad de la partida, los riesgos asumidos, el efecto del regreso a la casa en Estados Unidos. Su escritura es una estrategia de cuestionamiento y afirmación de la nueva identidad, previene el olvido y materializa las imágenes del viaje vinculadas a la ruptura de la mujer anterior; pero requiere el diálogo con Alicia para evitar engañarse y asegurar su apego a la realidad, lo emplea para ser corregida y reconducida en caso de incumplir o desviarse del propósito que las hizo coincidir en México.

La correspondencia de Teresa se lee entre líneas, en sus vacíos se adivinan las respuestas de Alicia no expuestas. En cambio, ya que las cartas de Genara y de Luisa aparecen ordenadas cronológicamente, es posible ver las transgresiones de los dos personajes, las posiciones que adoptan en las diversas situaciones que enfrentan y, así mismo, observar de qué manera, en su camino de búsqueda, se invierten perspectivas, puesto que a veces una, luego otra, generan la tensión del relato: escriben, solicitan una respuesta, leen y reflexionan para volver a la escritura y a la interpelación, repitiendo el circuito del diálogo.

En este doble proceso discursivo, los personajes femeninos escriben y reescriben, leen y releen las cartas. Traducen un conflicto personal en la escritura que, si bien se dirige a otra, está orientado a sí mismas; desde ese momento elaboran, tal como indica Bajtin, una respuesta previa. En 
cuanto a la respuesta, ésta puede o no ser la deseada, corresponder o no con lo que han previsto durante la escritura del mensaje. Genara y Luisa intercambian algunas cartas en las que prima la confusión debido a las diferencias de forma de pensar: de Genara influenciada por la familia, y de Luisa al adoptar el comportamiento de las mujeres en la ciudad de México: "Estoy de acuerdo contigo en que no tengo ni tu nivel intelectual ni tu experiencia, y que nunca he salido de Tijuana, sino de vacaciones; pero $[. .$.$] icrees, realmente, que no pueda tener una discusión contigo$ de esa naturaleza? No me subestimes, ¿sí?" (84).

Mientras esperan respuesta, los personajes de la novela de Conde suponen la aprobación o la crítica que llegará en la próxima carta. Al mismo tiempo reflexionan acerca de su proceder, si ha sido o no correcto, si recibirán el consejo solicitado o alguna retroalimentación de la decisión manifestada, ya en camino. Esto se percibe, además, por las respuestas inmediatas y apresuradas, o por la reacción a veces meditada y entusiasmada con la que escriben. Es común que en varios de sus mensajes Genara establezca reflexiones que ya muestren un cambio de actitud generado mientras esperaba respuesta: “Querida hermana: recibí tu carta y veo que tienes razón. ¡He sido una loca! [...] ¡Ojalá no esté cometiendo un error!” (39), o, “[s]í, sí, y reconozco que fui demasiado cruel, como bien lo dices en tu carta" (96).

En un mensaje de Luisa se presenta la reacción suscitada por la carta: “¿por qué la vida tiene que ser así de jodida, querida Genara? Desde que leí tu carta y la de mi madre, no he hecho otra cosa, sino patear todo lo que se me atraviesa" (49). La respuesta va cargada de intenciones, que a veces pueden ser propuestas, incitaciones para que la otra reaccione o vaya al enfrentamiento; se implica de manera práctica al provocar en su interlocutora una acción. Luisa, quien lee las lamentaciones de su hermana, todavía incapaz de romper su matrimonio y enfrentar a sus padres, envía el siguiente mensaje a su hermana: “¿Qué es lo que pretendes? ¿Por qué no te das un tiro de una vez? Ya te lo dije en una ocasión: salte de allí. ¿A qué le tienes miedo?: ¿al trabajo?, ¿a sentirte de nuevo traicionada?, ¿a tener que mantenerte?, ¿a la soledad, tal vez?" (81). Entonces, Genara, que se habría dado tiempo para releer sus quejas, le responde: “No sabes cómo me ayudó tu carta. En ningún momento las tomé como regaño. Realmente era eso lo que necesitaba: un jalón de orejas. Mi ánimo ha cambiado mucho" (83). Las cartas son efectivas en doble sentido: se produce una condición especular en la 
que los personajes femeninos son, unos frente a otros, figuras que se reflejan y se reconocen. De manera que, por ejemplo, el descontento con el que se acusa o reclama a la otra, no es más que una desaprobación dirigida a sí mismas y, por esta razón, cuando reciben una carta de indignación o de protesta, han asimilado ya el verdadero origen de su mensaje, con frecuencia errado, casi siempre movido por la frustración o el desconocimiento de sus posibilidades fuera del marco de opresión.

En el juego de correspondencia interviene, además, la significación del silencio, el vacío provocado por el retraso de las cartas. Después de un prolongado y continuo intercambio de éstas se establece un ritmo; la interrupción altera la comunicación y genera sentimientos de preocupación y angustia entre los personajes: “Querida Luisa: Hace tiempo que no me escribes. ¿Estás enojada conmigo? No, ¿verdá? Supongo que no lo has hecho porque tienes mucho trabajo y yo lo entiendo; pero, aunque sea, mándame un recadito para saber cómo estás" (122). La carta emitida exige con urgencia una respuesta aun cuando la "secuencia conversacional" (88) se presenta desfasada, confiere sentido a la correspondencia epistolar. (Violi, "La intimidad de la ausencia” 88).

Esta complicidad que caracteriza al diálogo epistolar entre mujeres juega un papel fundamental de su discurso, pues encuentran, en la solidaridad expresada mediante la escritura, una práctica colectiva crucial para ejercer su resistencia contra el orden patriarcal y los espacios sociales que las relegan. Las mujeres, refiere Luce Irigaray (2010), “quieren encontrarse, descubrirse, identificarse. De ahí su repliegue entre ellas, su amor entre ellas, su sociedad entre ellas" (97). Eso explicaría una parte de la efectividad de la escritura epistolar, el simulacro de un intenso intercambio retroalimentado en los mensajes de ida y vuelta en una de las novelas: "Formábamos una sociedad de mujeres, un triángulo sagrado" (Castillo 55), apunta Teresa.

Así pues, el viaje constituye una primera travesía fronteriza que comienza con la movilidad geográfica y acaba en cruces simbólicos que desestabilizan los límites de identidad y de género. En el caso de los personajes de la novela de Conde, hay un desplazamiento de la provincia, lugar cerrado, periférico, hacia el centro, lugar abierto y territorio libre. Sin embargo, para los personajes de la novela de Castillo, el cruce se realiza desde el espacio de libertad social hacia un entorno tradicional y moralmente opresivo. Pese a esta disparidad de trayectos, entre un relato y otro, el sentido de la movilidad física es similar en todos los 
personajes. El mapa es, finalmente, un plano de fondo para los cruces de los sujetos femeninos hacia un horizonte de libertad y redefinición de la identidad individual, sexual. Las cartas, extensiones de mayor alcance, más dinámicas aun que los mismos viajes, actúan como principales herramientas fronterizas, posibilitan el intercambio y promueven la reflexión de voces femeninas colectivas.

\section{Diálogos de transgresión: miradas especulares desde las fronteras}

La lectura comparativa de las cartas permite identificar el diálogo de los textos de ambos lados de la frontera México-Estados Unidos en relación con las experiencias de transgresión de las mujeres chicanas y de la frontera norte mexicana. Además del viaje, elemento significante que representa la primera forma de desplazamiento en esta interacción de discursos, intervienen otros cruces o claves de sentido relativos a la transición de los personajes femeninos en la configuración de sus identidades subjetivas.

Hasta aquí hemos distinguido una reflexión acerca de sí mismas, mediante la escritura, y una proyección de efectos especulares, que Patricia Violi (1991) define como la "experiencia de autoconsciencia", un espacio de reconocimiento en el que se permite a las mujeres expresar lo antes "no-dicho" y se convierte en un mecanismo que produce "significación y palabra" (156). En este ejercicio individual de autoconsciencia, las mujeres encuentran su parte de realidad única, pero también su subjetividad, su unión con las otras, es decir, admiten lo que las hace "individualmente distintas, infinita multiplicidad de 'yo' singular" (156). Desde esta perspectiva pueden identificarse diversos asuntos "no-dichos" compartidos por los personajes femeninos de ambos textos, teniendo en cuenta los puntos de contacto que derivan en un hilo común, pero, igualmente, las diferencias.

Primero, en las cartas de ambas novelas, destaca como elemento principal la escritura donde los sujetos femeninos cuestionan la visión del matrimonio determinada por los códigos religiosos y morales, transmitidos entre familias durante generaciones: “Pero un matrimonio por la Iglesia no se rompe nunca, Genara!, ¡acuérdate de eso!" (Conde 28), pronuncian la madre y la madrina de Teresa, quienes le advierten que, "según la Iglesia, aunque te divorcies siempre estarás casada y 
vivirás en el pecado" (Castillo 25). Teresa repite estas frases aprendidas de memoria en su carta a Alicia para prevenirla de que, durante su visita a Los Ángeles, a la casa familiar, deberá cuidarse de hablar sobre el tema del matrimonio, pues sus parientes se escandalizarán al enterarse de que a sus treinta años nunca se ha casado (24). Respecto al matrimonio, los mensajes intercambiados aportarían material suficiente para realizar una lista de creencias, tradiciones y principios a seguir; a partir de estas prácticas impuestas se construye un imaginario que ordena el quehacer diario de las mujeres y traza los límites que frenan la realización de sus inquietudes personales.

La ruptura de las mujeres con este oden provoca el rechazo entre la mayoría social. Las dos chicanas entienden, durante su visita a México, que su principal transgresión ha sido "viajar solas" (88) y, enseguida, desafiar a los hombres que confundieron su independencia con libertinaje, cuando éstas mostraban inconformidad y capacidad de defenderse. Hablar abiertamente se convierte en un arma, comienza a activarse en el ejercicio de la escritura epistolar, allí se elaboran las primeras expresiones subversivas y reveladoras para los próximos cambios. Sin embargo, las mujeres tienen que asumir, según expone Teresa, que, al adquirir libertad, la sociedad las convierte en "defectos sociales", "malas esposas", “mala gente”, “de reputación dudosa”. Genara se resiste a seguir las reglas de la estructura familiar, así que, a través de una carta a su marido, anuncia que traicionará a sus amigas, pero que no habrá de callarse. Confiesa que no piensa igual que ellas, pues no tiene miedo a la soledad y no está dispuesta a reconciliarse (Conde 18). Igual que Teresa, Genara concluye que finalmente las mujeres que toman tales decisiones acaban siendo siempre "las malas de la película", "verdaderas tiranas", "inmorales", "brujas".

Así mismo, el comportamiento sexual de los personajes femeninos se modifica de manera similar en las dos novelas. En medio de este proceso de reconstrucción de la identidad el celibato se considera, en un principio, un camino "para alcanzar la autosuficiencia”, según las palabras de Teresa (Castillo 154). La abstinencia se ejerce como estrategia de negación y resistencia frente al sujeto opresor, en respuesta a la sociedad que valora la apariencia física femenina a partir de ideales sobre cuerpos perfectos o figuras de "muñeca" (169), limitadas al espacio de la casa, según repudia Teresa. Desde los dos espacios epistolares se describe la falta de interés sexual, indiferencia que las mujeres atribuyen a su 
ocupada vida profesional. Teresa habla de experimentar "enajenación” en sus relaciones, mientras que Luisa expresa cómo se ha convertido en un eunuco, egoísta y solitaria. El vínculo de la sexualidad con el amor, indisociable moralmente, se rompe cuando las mujeres aceptan su capacidad de tener relaciones sexuales, como escribe Genara en una carta, "sin estar enamoradas" (Conde 144) y motivadas, más bien, por la necesidad de conocimiento de sus propios cuerpos, por curiosidad y para desafiar los prejuicios morales. Para Teresa, el amor es equivalente a la "humillación", "significa rendirse a un hombre" (Castillo 161). En una carta define el corazón de Alicia, quien renunció a la espera del príncipe soñado; como "un órgano que bombea sangre, más que como la metáfora romántica” (174). En ambas novelas hay una declaración del cuerpo femenino inicialmente supeditado al reconocimiento del hombre $\mathrm{y}$, posteriormente, definido como territorio bajo el poder de las mujeres. En una de las últimas cartas, Genara comprende que la independencia se consigue en la medida en que se percibe y acepta a sí misma, sin necesidad de aprobación del sujeto masculino, pues, señala: “todo cambia cuando asumimos que podemos vivir por nosotras mismas y para nosotras mismas. Yo creo que si una está contenta consigo misma, los demás lo estarán también con una" (Conde 157). Durante la experiencia de opresión, los personajes entienden, por aprendizaje social, que el cuerpo femenino "significa" solo para el hombre y "es" en función de lo que éste construye en su necesidad de identificarse. En el caso de Teresa, finalmente concluye la razón por la cual Alicia se "odiaba" antes de "iniciar el proceso metódico de reunir [sus] pedazos" (Castillo 163), de conseguir un trabajo y de la visitas con el psicólogo:

No eras la deseable, suave, sin complicaciones, maternal/infantil, seno, abrazo y arrullo perpetuo, rubia, vivaz, con labios fruncidos color cereza, estrella de plástico de las películas de Hollywood, virgen santa, ni cualquier imagen, ilusión, delirio, alucinación, reproducción brillante de celuloide, estereotipo, definición trillada del hombre de lo que es y debe ser una mujer. Por lo tanto no serías amada. (163)

Tres cartas más adelante, Teresa escribe lo que ocurrió después a su amiga: un embarazo no deseado que concluyó con un aborto, el cual pudo realizarse legalmente al presentarse bajo la identidad de una puertorriqueña que había tenido cinco hijos y que no quería tener más. La sexualidad desligada de la censura y la exigencia masculina, centrada 
en la posibilidad del deseo femenino, así como la factibilidad del aborto voluntario, representan claves de la nueva conciencia de las mujeres acerca de sus cuerpos, así como la fragmentación de las trampas de la “utopía romántica” acerca del amor, que no es más que otra práctica de consumo capitalista (Illouz, 2010), en una sociedad en la que actúan por inercia y no por convicción. Una vez que cuestionan estos principios, el deseo y el placer son hechos legítimos para las mujeres. El placer antes negado requiere ser descubierto para establecer, como señala Graciela Hierro (2003), una "ética sexual" que les permita regularlo. Parte con el empoderamiento del cuerpo y redunda, según la visión de esta autora, en la recuperación total de su vida y en un posicionamiento más justo dentro de la sociedad (124). Pero sobre todo, el reconocimiento del deseo de la mujer permite, como propone Cixous (1995), rebatir los fundamentos psicoanalíticos de Freud acerca de la diferencia de lo femenino en función de lo masculino (48). Al contrario, el cuerpo de la mujer y su deseo constituyen “zonas privilegiadas de búsqueda, exploración y creación gozosas" (Curbet 19), condición desde la cual "le es posible leer, escribir y vivir en términos de transformación positiva" (19).

No obstante, hay una paradoja entre el discurso de resistencia cuando finalmente los personajes femeninos admiten la necesidad del sujeto masculino, de manera que no lo pueden rechazar totalmente. La conciencia de las mujeres sobre sí mismas, revela, casi al final del camino de reafirmación, la imprescindible presencia del otro para construir el yo. Esta aceptación representa un momento de tensión, puesto que contradice el impulso liberador que las empuja a alejarse del hombre. Genara escribe a Fidel, su pareja después del divorcio, lo que no se atreve a decir a su hermana, quien ha llegado al extremo del aislamiento en su proceso de emancipación: que "el matrimonio fue siempre el motor de nuestras vidas, y aunque Luisa ha tratado de engañarse haciéndose creer que el amor no es el motivo de su existencia, es precisamente la falta de amor lo que la está matando" (Conde 187). Esta contradicción revela un aspecto aún no resuelto en medio de las convicciones sobre su nueva condición libre. Tiene que ver con el reconocimiento de los afectos, incluido el amor, como una práctica que subyace y se impone en la conformación de las identidades de los sujetos. Teresa, cuando en una ocasión siente la necesidad urgente de escapar, expresa que elige como primera opción llamar a alguien conocido, su exmarido, tomar un avión 
con el propósito de encontrarlo. Para justificarse, argumenta que no es desesperación lo que la impulsa, sino una sensación, una "tripa de gato que liga a quienes han vivido dificultades juntos y han compartido buenas épocas" (Castillo 183). Esta conciencia sobre el amor, traducida como asimilación de la otredad, parece originarse del amor propio desarrollado a partir del proceso de búsqueda interior. En ese sentido, Luisa, según el recuerdo escrito por Teresa, había encontrado un departamento que pagaría con sus propios recursos y, sin embargo, algo todavía le inquietaba: "la falta de algo que no podías definir, a menos que fuera la naturaleza, doblegaba tu cuerpo y tu espíritu a pesar de los obstáculos de la sociedad. Los hombres y las mujeres debían destar juntos [...] Eran socios en el sentido más profundo" (155). El autoconocimiento les permite aceptar la necesidad de vincularse con el otro, comprender que su lucha de empoderamiento implica gestionar las relaciones de poder bajo las cuales han intentado convivir y han fracasado por generaciones.

\section{Conclusiones}

Los escenarios representados en las novelas de Rosina Conde y Ana Castillo refieren, por un lado, espacios exteriores de viaje y búsqueda. La casa deja de ser el lugar de construcción de la identidad para las mujeres, deja de considerarse el lugar de las ensoñaciones, tal como propone Bachelard (2013), el cual señala que sin ésta "el hombre se encontraría disperso" (37). A cambio del lugar fijo, asociado positivamente a la idea de identidad y de arraigo, el viaje se convierte en la experiencia que permite a las mujeres redefinirse desde subjetividades "nómades" (Braidotti, 2004). Así, a la habitación propia para las mujeres, reclamada por Virginia Woolf (2005), se agregarían las habitaciones transitorias, acordes con su condición fronteriza y prácticas de movilidad. La ruptura con el sistema opresor del núcleo familiar, de la casa matrimonial y, en general, del centro dictador de códigos sociales y culturales, es lo que en principio motiva la huida y reflexión de los personajes femeninos acerca del conocimiento de sí mismas.

El intercambio epistolar activa el juicio de los personajes femeninos, pues en sus desplazamientos y confrontación de valores, cuestionan y evalúan las prácticas guiadas por la tradición patriarcal. Mediante la escritura, las mujeres experimentan un encuentro especular con 
la otra mujer, en el que reconocen su subjetividad y la posibilidad de empoderamiento de sus cuerpos y sus actos.

La comparación de las novelas epistolares de ambas autoras de la literatura de la frontera mexicana y chicana, según la propuesta metodológica de estudio bifronterizo, permite reconocer significaciones comunes entre ambos discursos fronterizos, específicamente, en la experiencia del viaje y el ejercicio de la escritura epistolar como estrategia de resistencia. No obstante, son visibles también las diferencias entre los sujetos femeninos de ambos espacios, pues aunque en sus cartas es evidente la necesidad de búsqueda de nuevas identidades y el quiebre de los patrones asociados al dominio patriarcal, las mujeres chicanas, dentro de las dinámicas de vida de la sociedad estadounidense, demuestran mayor asimilación de sus diferencias sociales, raciales y de género y, por lo tanto, se adelantan en su proceso de búsqueda reivindicadora; mientras que las mexicanas, arraigadas al espacio familiar y tradicionalista en una región de provincia, incorporan paulatinamente este reconocimiento. El diálogo entre ambos textos radica en la efectividad del intercambio epistolar dentro de las prácticas de transgresión de los sujetos femeninos. En tanto proceso de apertura y de cruce, inscribe una práctica cultural y un acto performativo contra las estructuras dominantes.

\section{Referencias bibliográficas}

Anzaldúa, Gloria. Borderlands/ La frontera. The New Mestiza. San Francisco, Aunt Lut Books, 1987.

Bachelard Gaston. La poética del espacio. México, D.F., Fondo de Cultura Económica, 2013.

Bajtin, Mijail. Estética de la creación verbal. Trad. Tatiana Buvnova. México, D.F., Siglo Veintiuno Editores, 1999.

Braidotti, Rosi. Feminismo, diferencia sexual y subjetividad nómade. Barcelona, Gedisa Editorial, 2004.

Butler, Judith. El género en disputa: el feminismo y la subversión de la identidad. Madrid, Paidós Ibérica, 2007.

Braidotti, Rosi. Feminismo, diferencia sexual y subjetividad nómade. Barcelona, Gedisa Editorial, 2004.

Cárdenas Contreras, Antonio. Mar, desierto y ladrillo. Hacia una dialéctica de la liberación de la frontera. California, Orbis Press, 2008. 
Castillo, Ana. Las cartas de Mixquiahuala. México, D.F., Grijalbo, 1994.

Castillo, Debra A. Easy Women. Sex and Gender in Modern Mexican Fiction. Minneapolis, University of Minnesota Press, 1998.

Ciplijauskauté, Biruté. "La construcción del yo y la historia en los epistolarios". Monteagudo, no.3, 1998, pp. 61-72.

Cixous, Helène. La risa de la medusa. Ensayos sobre la escritura. Trad. Ana María Moix. Madrid, Editorial Anthropos, 1995.

Conde, Rosina. La Genara. México, D.F., Universidad Autónoma de la Ciudad de México, 2006.

Curbet Soler, Joan. Figuras del deseo femenino. 12 representaciones de la mujer en la literatura occidental. Madrid, Ediciones Cátedra, 2014.

Doll Castillo, Darcie. “La carta privada como práctica discursiva. Algunos rasgos característicos”. Revista Signos, no. 35, 2002, pp. 33-57.

"Las cartas de amor de Gabriela Mistral o el discurso amoroso de una sujeto en fuga". Modernidad en otro tono. Escritura de mujeres latinoamericanas 1920-1950. Alicia N. Salomé, Gilda Luongo, Natalia Cisterna, Darcie Doll y Graciela Queirolo. Santiago de Chile, Editorial Cuarto Propio, 2004.

Fernández Cordero, Laura. “Cartas y epistolarios. Lecturas sobre la subjetividad”. Revista Políticas de la Memoria, no. 14, 2013, pp. 23-29.

Foucault, Michel. La hermenéutica del sujeto. Curso en el Collége de France (1981-1982). Trad. Horacio Pons. México, D.F., Fondo de Cultura Económica, 2012.

Guillén, Claudio. Múltiples moradas. Ensayo de Literatura Comparada. Barcelona, Tusquets, Editores, 2007.

Hernández, Manuel de Jesús. "De la crítica borderlands a la crítica biborderlands: Un nuevo discurso crítico descentrado y antihegemónico para los estudios literarios y culturales de la frontera México-Estados Unidos”.Chican@symexican@ snorteñ@s.Bi-borderlands dialogues on literary and cultural production. Eds. Graciela Silva Rodríguez y Manuel de Jesús Hernández. México, D.F., Ediciones Eon/Arizona State University, 2012, pp. 30-63. 
Hierro, Graciela. La ética del placer. México, D.F., Diversa / Universidad Autónoma de México, 2003.

Hintze, Gloria y Maria Antonia Zandanel. “Algunas nociones sobre el género epistolar a propósito de las cartas de Francisco Romero". Revista Cuyo, vol. 29, no. 2, 2012, pp. 13-33.

Illouz. El consumo de la utopía romántica. El amor y las contradicciones culturales del capitalismo. Trad. María Victoria Rodil. Madrid, Kats Editores, 2010.

Irigaray, Luce. Ética de la diferencia sexual. Pontevedra, Ellago Ediciones, 2010.

Klahn, Norma. “Travesías/travesuras: Des/vinculando imaginarios culturales". Renacerá la palabra. Identidades y diálogo intercultural. Ed. José Manuel Valenzuela Arce. Tijuana, Colegio de la Frontera Norte, 2003, pp. 111-127.

Quintana, Alvina E. “Ana Castillo’s The Mixquiahuala Letters: The Novelist as Ethnographer". Criticism in the Borderlands. Studies in Chicano Literature, Culture and Ideology. Ed. Héctor Calderón y José David Saldívar. United States, Duke University Press, 1994.

Martin, Cointa G. Mundos prohibidos: el poder en el discurso epistolar de Gertrudis Gómez Avellaneda y Juana Borredo. Tesis. Florida International University, 2012.

Sandoval, Anna Marie. Toward a Latina Feminism of the Americas. Repression and Resistance in Chicana and Mexicana Literature. Austin. University of Texas Press, 2008.

Silva Rodríguez, Graciela. La frontera norteña femenina. Transgresión y resistencia identitaria en Esalí, Conde y Rivera Garza. México, D.F., Ediciones Eón, 2010.

Tabuenca Córdoba, María Socorro. “Aproximaciones críticas sobre las literaturas de las fronteras". Frontera Norte, vol. 9, no. 18, juliodiciembre de 1997, pp. 85-110.

"Las literaturas de las fronteras". Por las fronteras del norte: una aproximación cultural a la frontera México-Estados Unidos. Coord. José Manuel Valenzuela Arce. México, D.F., Fondo de Cultura Económica, 2013, pp. 393-424. 
Torras Francés, Meri. Tomando cartas en el asunto. Las amistades peligrosas de las mujeres con el género epistolar. Zaragoza, Prensas Universitarias de Zaragoza, 2001.

Violi, Patrizia. El infinito singular. Trad. José Luis Aja, Carmen Borra y Marina Caffaratto. Madrid, Ediciones Cátedra, 1991.

"La intimidad de la ausencia: formas de la estructura epistolar". Revista de Occidente, no. 68, 1987, pp. 87-99.

Woolf, Virginia. Una habitación propia. Trad. Laura Pujol. Barcelona, Seix Barral, 2005. 